\title{
The Afferent and Efferent Pathways of the Recto-colonic Reflex in the Dog
}

\author{
Hiroyuki FukUda and Kiyoko FuKaI \\ Department of Physiology, Kawasaki Medical School, \\ Kurashiki, Okayama, 701-01 Japan
}

\begin{abstract}
The nature of the afferent and efferent pathways of the rectocolonic reflex was studied electrophysiologically in the dog. A compound action potential consisting of many peaks was evoked on a sacral dorsal rootlet by a stimulus to the ipsilateral rectal strands of the pelvic nerve. Conduction velocities of the peaks indicate that $\mathrm{A} \delta$ and $\mathrm{C}$ afferent fibers innervate the colon and rectum. When the stimuli were subthreshold for $\mathrm{C}$ fibers, the reflex discharges of contralateral parasympathetic post-ganglionic fibers in the rectal strands and the reflex contraction of the colon were smaller than those caused by stronger stimuli. As the intensity of the stimulus to the sacral ventral roots was weakened, response peaks of preganglionic $\mathrm{B}$ fibers in the rectal branch, post-ganglionic $\mathrm{C}$ fibers in the rectal strands and a bladder branch of the pelvic nerve disappeared in the order of slow to fast conduction velocities. Contraction of the colon also decreased. The number of peaks arising from each nerve correlated well with the strength of the contraction. These results indicate that the peripheral limbs of the recto-colonic reflex arc consist of afferent $\mathrm{A} \delta$ and $\mathrm{C}$ fibers, preganglionic $\mathrm{B}$ fibers and post-ganglionic $\mathrm{C}$ fibers.
\end{abstract}

Key words: recto-colonic reflex, pelvic nerve, parasympathetic nerve, defecation.

It has long been known that a propulsive contraction of the distal colon and rectum is induced reflexively by their distension (GARRY, 1933). Both the afferent and efferent pathways of this recto-colonic reflex are in the pelvic nerve. DE GroAT and KrIER $(1975,1976,1978)$ reported that both pathways are composed of $\mathrm{C}$ fibers in cats. However, experiments in dogs have shown that a spinal reflex with a short latency of about $50 \mathrm{msec}$ and a long latency reflex via the pontine defecation reflex center make up the recto-colonic reflex (FUKUDA et al., 1981; OKADA et al., 1975, 1976). The latency in the spinal reflex seems to be too short to be consistent with the conduction time of $\mathrm{C}$ fibers in both afferent and efferent pathways. The aim of this study is to resolve this contradiction.

Received for publication April 24, 1985 


\section{METHODS}

This study was carried out on 18 dogs weighing 5-12 kg. Conduction velocities of colonic afferent fibers ( $3 \mathrm{dogs}$ ) and threshold stimulation to preganglionic fibers serving fibers innervating the colon and bladder $(7 \mathrm{dogs})$ were measured in dogs anesthetized with intravenous $\alpha$-chloralose $(100 \mathrm{mg} / \mathrm{kg})$. The threshold at which stimulation of colonic afferent fibers elicites the recto-colonic reflex was examined in 8 dogs decerebrated precollicularly under anesthesia with an intramuscular injection of ketamine hydrochloride $(10 \mathrm{mg} / \mathrm{kg})$. The ventral and dorsal roots of the three left sacral nerves were isolated by a laminectomy from L4 to S3. The pelvic nerve, its bladder branches, its rectal branch, and the rectal strands were exposed by an incision along the inguinal ligament. The rectal branch bifurcates from the pelvic nerve and enters into the extramural colonic ganglia (Figs. $2 \mathrm{~h}$ and $3 \mathrm{G}$ ). The rectal strands arise from the ganglia and invade the colonic wall after an ascending course $(3-4 \mathrm{~cm})$ on the serosal surface of the colon. These branches of the pelvic nerve and the rootlets of the sacral cord were simultaneously stimulated and recorded with bipolar platinum wire electrodes with the dog lying on its right side. Post-stimulus discharges of such nerve starnds were amplified with the amplifiers (time constant, $0.003 \mathrm{sec}$ ) and averaged with a digital computer (Signal processor, 7T08, NEC San-ei Inst. Ltd., Japan). Reflex discharges of rectal strands were induced by stimulation of colonic afferent fibers in the contralateral rectal strands. The reflex discharges were fed into a spike counter and converted into frequency histograms of $1 \mathrm{sec}$ bins. The lumbar colonic nerve and the bilateral hypogastric nerves were severed in all cases. The exposed nerves were covered with warmed mineral oil. The intraluminal pressure of the distal colon was measured with a water filled rubber condom positioned 3-6 $\mathrm{cm}$ above the rostral border of the area, where the rectal strands invade the colonic wall.

Dogs were paralyzed with intravenous gallamine triethiodide $(1 \mathrm{mg} / \mathrm{kg})$, then artificially ventilated through a tracheal cannula at a rate of 30 to 35 strokes/ min and a tidal volume of 50 to $150 \mathrm{ml}$. Body temperature was maintained at about $36^{\circ} \mathrm{C}$ by the heat from two $100 \mathrm{~W}$ tungsten lamps.

\section{RESULTS}

Type of fiber in the afferent pathway of the recto-colonic reflex

To measure conduction velocities of the colonic afferent fibers, the central cut ends of rectal strands were stimulated, and the response of a dorsal rootlet of the ipsilateral sacral nerves was recorded by two electrodes. Discharges corresponding to the stimulation could not be observed because of interference from spontaneous discharges. Clear peaks, however, appeared as shown in Fig. 1, when 200 responses were averaged. In this case, the conduction time of the first $\mathrm{A} \delta$ fiber peak was $2.4 \mathrm{msec}$, and that of the $\mathrm{C}$ fiber peak was $37.5 \mathrm{msec}$. Conduction 


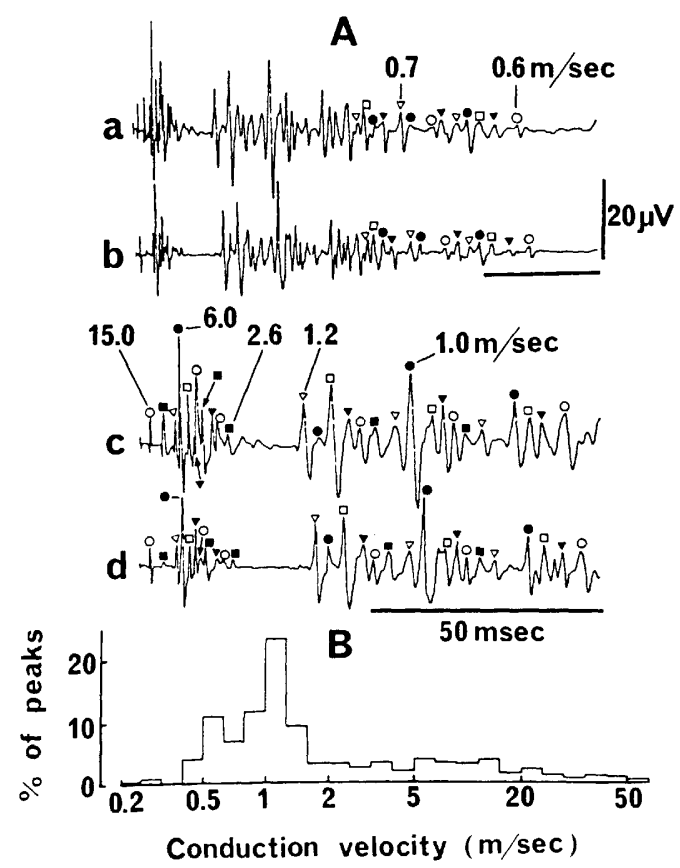

Fig. 1. Conduction velocities of colonic afferent fibers in the pelvic nerve. A: responses of a dorsal rootlet to stimulation of central cut ends of the ipsilateral rectal strands. The stimulation was by pulses of $0.5 \mathrm{msec}$ duration, $0.5 \mathrm{~Hz}$ and $10 \mathrm{~V}$. The responses in $a$ and $b$ to the same stimulating pulse were recorded with two electrodes separated by $5 \mathrm{~mm}$ on one dorsal rootlet. Records of $\mathrm{c}$ and $\mathrm{d}$ were the same as a and $\mathrm{b}$ except that the time axis was doubled. Corresponding peaks in each pair of recordings are indicated by the same symbol. The conduction velocities of some peaks are shown. B: conduction velocities of 536 peaks.

velocities were calculated from the delay times between corresponding peaks.

The conduction velocities calculated from 536 pairs of peaks of 34 dorsal rootlets in three dogs are shown in Fig. 1B as a histogram. Distribution of the velocities shows that $\mathrm{A} \delta$ and $\mathrm{C}$ afferent fibers are in the rectal strands. About $70 \%$ of the peaks had a velocity of under $2 \mathrm{~m} / \mathrm{sec}$, and the mean conduction velocity was $1.0 \pm 0.4 \mathrm{~m} / \mathrm{sec}$ (mean \pm S.D., $n=393$ ). The mean conduction velocity of the remaining $30 \%$ of the peaks was $10.8 \pm 10.2 \mathrm{~m} / \mathrm{sec}(n=143)$.

The type of fiber comprising the afferent pathway of the recto-colonic reflex was determined by eliciting the reflex with a 1,000 train pulse, $10 \mathrm{~Hz}$ stimulus to the afferent fibers in the rectal strands (Fig. 2). The action potentials of the afferent fibers were recorded with $\mathrm{R} 1$ from the pelvic nerve and averaged during the stimulus (Fig. 2 A-G). Simultaneously, the reflex contraction of the distal colon and reflex discharges of one contralateral rectal strand were recorded with a balloon (R3) and R2, respectively (Fig. 2a-g). The intensity of the stimulus was 


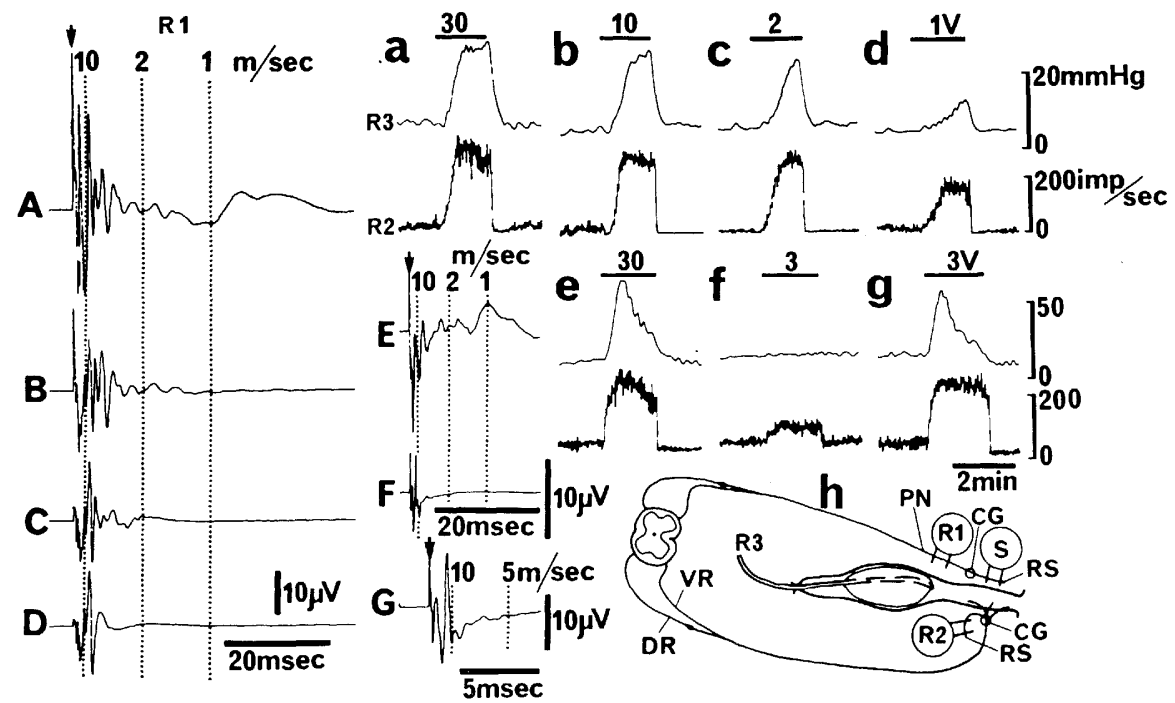

Fig. 2. Afferent fiber types of the recto-colonic reflex. The electrodes were arranged as shown in $\mathrm{h}$. $\mathrm{R} 1$ and $\mathrm{R} 2$, recording electrodes; R3, a tube connecting the balloon to a pressure transducer; DR, dorsal rootlets; VR, ventral rootlets; CG, extramural colonic ganglia; RS, rectal strands; $\mathrm{S}$, stimulating electrode. The same abbreviations are used in Fig. 3. Rectal strands were stimulated by 1,000 train pulses of $10 \mathrm{~Hz}, 0.06 \mathrm{msec}$ duration and the intensities indicated in a-g. Horizontal bars in a-g indicate stimulating periods. Arrows in A, E, and $\mathrm{G}$ show stimulation artifacts. Vertical dotted lines in $A-G$ show the time scales as conduction velocities. A-D and a-d were recorded from one decerebrated dog and $\mathrm{E}-\mathrm{G}$ and $\mathrm{e}-\mathrm{g}$ from another. The distance between electrodes $\mathrm{S}$ and $\mathrm{R} 1$ was $25 \mathrm{~mm}$ in $\mathrm{A}-\mathrm{D}$ and $15 \mathrm{~mm}$ in $\mathrm{E}-\mathrm{G}$. $\mathrm{G}$ and $\mathrm{g}$, these responses were elicited by the same pulses as $\mathrm{F}$ and $\mathrm{f}$, but repeated 3,000 times with $30 \mathrm{~Hz}$.

weakened from 30 (Fig. 2A, a) to 10 (Fig. 2B, b), 2 (Fig. 2C, c), and 1 (Fig. 2D, d) $\mathrm{V}$. The number and amplitude of $\mathrm{C}$ fiber peaks of conduction velocity less than $2 \mathrm{~m} / \mathrm{sec}$ decreased in response to the $10 \mathrm{~V}$ stimulus (Fig. 2B), and the peaks disappeared completely in the responses to the 2 and $1 \mathrm{~V}$ stimuli (Fig. 2C, D). A $\delta$ fiber peaks also decreased in number and amplitude in response to the 2 and $1 \mathrm{~V}$ stimuli (Fig. 2C, D). As peaks of $\mathrm{C}$ and $\mathrm{A} \delta$ fibers decreased, the reflex discharges of the contralateral rectal strand and the reflex contraction of the distal colon decreased (Fig. 2b, c, d); however, the latter were elicited by the $1 \mathrm{~V}$ stimulus, which activated only the fast $\mathrm{A} \delta$ firbers (Fig. 2D, d).

Figure $2 \mathrm{E}-\mathrm{G}$ shows another example of the experiment. In this case, the reflex contraction was not caused by the 1,000 pulse, $10 \mathrm{~Hz}, 3 \mathrm{~V}$ stimulus (Fig. 2f), which elicited only A $\delta$ fiber peaks (Fig. 2F). When the stimulus was increased to 3,000 pulses of $30 \mathrm{~Hz}$, the reflex discharges increased and casued a reflex contraction (Fig. 2g). They were comparable to the reflex effects elicited by the 1,000 pulse, $10 \mathrm{~Hz}, 30 \mathrm{~V}$ stimulus (Fig. 2e), which pulses were supramaximum for $\mathrm{C}$ as well as A $\delta$ fibers. Both results were confirmed with similar experiments per- 
formed in 5 other dogs.

The results show that the recto-colonic reflex is elicited by afferent impulses of $\mathrm{C}$ as well as $\mathrm{A} \delta$ fibers, but the reflex could be elicited near its maximum by high frequency impulses of A $\delta$ fibers alone.

Type of preganglionic fiber serving the fibers innervating the colonic smooth muscle

During stimulation of the sacral ventral roots by 100 pulses of $2 \mathrm{~Hz}$, responses of a preganglionic rectal branch, a post-ganglionic rectal strand and a bladder branch were simultaneously averaged, and contraction of the distal colon was measured (Fig. 3). In this case, the conduction time for the first post-ganglionic $\mathrm{C}$ fiber peak of the rectal strand was $30.2 \mathrm{msec}$. As the intensity of the stimulus weakened, response peaks of the three nerves disappeared in the order of slow to fast conduction velocities, in parallel with a decrease in the colonic contraction (Fig. $3 \mathrm{~A}-\mathrm{F})$. Correlation coefficients were calculated between the number of peaks in

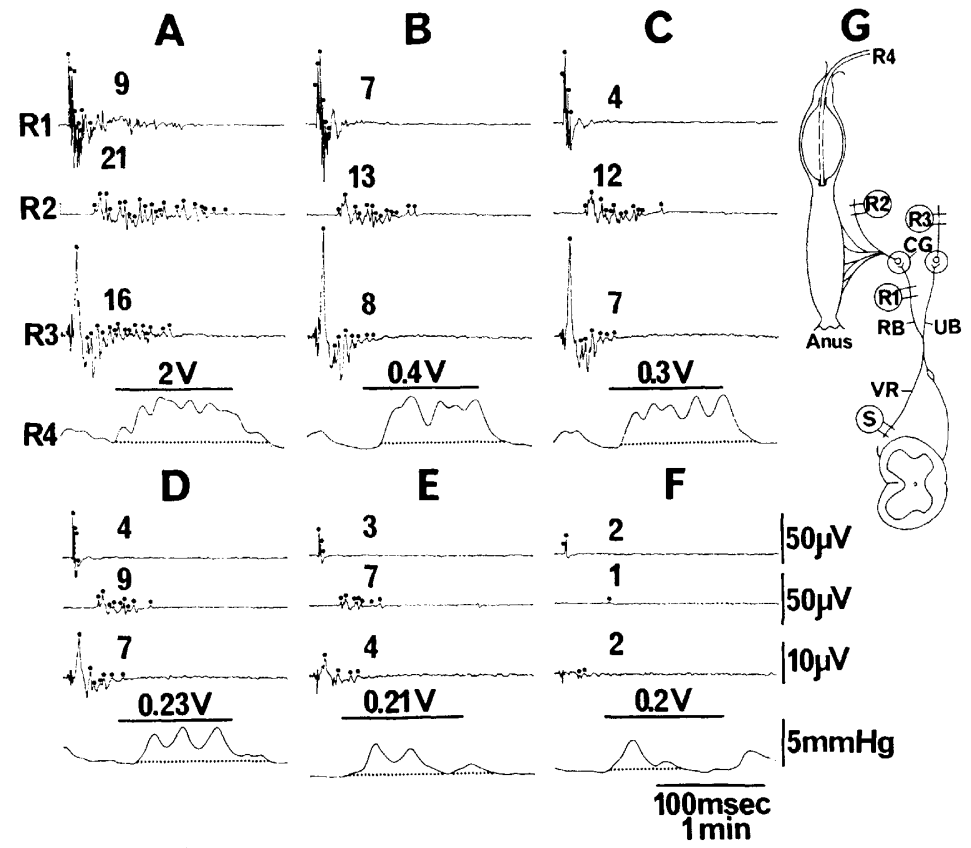

Fig. 3. Threshold stimulation for the sacral parasympathetic preganglionic fibers serving the fibers innervating the distal colon and urinary bladder. The electrode arrangement for this experiment is shown in G. Contraction of the distal colon was induced by simultaneous stimulation of ventral roots of the first and second sacral nerves. Pulses of $0.5 \mathrm{msec}$ duration, $2 \mathrm{~Hz}$ and the intensities shown above the horizontal bar over the recording of R4 in A-F, are shown. The bar indicates the stimulating period. Responses of a rectal branch (R1), a rectal strand (R2), and a urinary bladder branch (R3) were averaged 100 times during the stimulation. $R 4$, a tube connecting the balloon to a pressure transducer.

Vol. 35, No. 5, 1985 
the nerve responses and the strength of the colonic contractions. The strength of the contraction is represented by the area above the dotted line shown in Fig. $3 \mathrm{~A}-\mathrm{F}$. The peaks counted in the nerve responses are indicated by dots in the figure. The correlation coefficients were $0.81,0.86$, and 0.91 for responses of the bladder branch, the preganglionic $\mathrm{B}$ fibers in the rectal branch and the postganglionic $\mathrm{C}$ fibers in the rectal strand, respectively. Similar results were obtained in 6 other dogs.

This result shows that the sacral parasympathetic pathway innervating the colonic smooth muscle comprises preganglionic $\mathrm{B}$ fibers and post-ganglionic $\mathrm{C}$ fibers, as in the pathway to the urinary bladder.

\section{DISCUSSION}

Afferent fibers of the recto-colonic reflex. The recto-colonic reflex was elicited by afferent impulses of $\mathrm{C}$ as well as $\mathrm{A} \delta$ fibers, and the reflex could be elicited near its maximum by high frequency impulses of A $\delta$ fibers alone (Fig. 2). DE GROAT and KRIER (1978) reported that reflex discharges of sacral parasympathetic postganglionic fibers to the colon were only elicited when colonic afferent fibers in the pelvic nerve was stimulated by single or short train pulses of an intensity higher than the threshold of $\mathrm{C}$ afferent fibers in chloralose anesthetized cats, and concluded that the recto-colonic reflex is mediated by $\mathrm{C}$ afferent fibers. Their records of the reflex discharges were obtained from a nerve filament which arises from the extramural colonic ganglia and runs on the serosal surface of the mid-distal colon of the cat. Because we used the terms of "rectal strand" to express the corresponding nerve filament of the dog, it is expected reasonably that the recto-colonic reflex studied in this work correspond with the reflex investigated by DE GROAT and KRIER (1978).

As their results were based on experiments with cats, the difference in the results may be due to the difference in the experimental animals. There are, however, other possibilities. The recto-colonic reflex is elicited by A $\delta$ afferent fibers alone, and only when temporal summation of their high frequency impulses is performed as shown in Fig. 2. Therefore, single or short train pulse stimulation of A $\delta$ fibers may just barely elicite the reflex. In our experience, chloralose brings about a weak depression of the reflex, so the anesthetic used in the cats may have contributed to the different results as well. Also, the rectal strands of the pelvic nerve were stimulated to elicite the reflex in the dog in our study. However, the pelvic nerve itself was stimulated in the cat in the experiments performed by DE GrOAT and KRIER (1978) to elucidate afferent fiber types of reflex. Vesical afferent fibers in the pelvic nerve may be activated by stimulation of the pelvic nerve itself, and may elicite a micturition reflex which reciprocally inhibits the rectocolonic reflex (FuKudA et al., 1983).

Efferent fibers of the recto-colonic reflex. We measured the conduction ve- 
locity of the sacral parasympathetic nerve innervating the colon of dogs (FUKAI and FukUda, 1985). The results show that most of the preganglionic fibers are B fibers and most of the post-ganglionic fibers are $\mathrm{C}$ fibers. Furthermore, it was determined in this study that preganglionic $\mathrm{B}$ and post-ganglionic $\mathrm{C}$ fibers work together in innervation of the colonic smooth muscle. DE GROAT and KRIER $(1975,1976)$, however, observed that the threshold stimulation of the sacral ventral roots to evoke discharges of the post-ganglionic fiber to the colon and colonic contraction was higher than that to evoke discharges of the post-ganglionic fibers in the urinary bladder and vesical contraction. From the results, they concluded that the preganglionic fibers serving fibers innervating the colonic smooth muscle of the cat are $\mathrm{C}$ fibers. Further study will be required to elucidate whether or not a difference between the species truly exists.

In the reflex response of rectal strands of the pelvic nerve to stimulation of central cut ends of the contralateral rectal strands, an initial short discharge, which is followed after a silent period by a long lasting late discharge, is observed in the dog (FuKUDA et al., 1981; OKADA et al., 1975, 1976). The initial short discharge seems to be evoked via a spinal reflex arc, because the discharge was observed in the spinal dog. The discharge appears after about a $50 \mathrm{msec}$ latency and lasts 120-130 msec after the stimulation. The latency cannot be explained by the conduction time of a reflex arc consisting of afferent and efferent $\mathrm{C}$ fibers, because the conduction times of the fastest $C$ afferent fibers are about $40 \mathrm{msec}$ as shown in this study. However, the conduction time of the afferent $\mathrm{A} \delta$ fibers (about $5 \mathrm{msec}$ ) and of the efferent pathway, preganglionic $B$ fibers and post-ganglionic $C$ fibers (about $30 \mathrm{msec}$ ) is consistent with the short latency of the spinal element of the recto-colonic reflex.

\section{REFERENCES}

FukaI, K. and Fukuda, H. (1985) Three serial neurons in the innervation of the colon by the sacral parasympathetic nerve of the dog. J. Physiol. (Lond.), 362: 69-78.

Fukuda, H., Fukai, K., Yamane, M., and Okada, H. (1981) Pontine reticular unit responses to pelvic nerve and colonic mechanical stimulation in the dog. Brain Res., 207: 59-71.

FuKudA, H., FuKaI, K., and OKada, H. (1983) Effects of vesical distention on parasympathetic outflow to the colon of dogs. Kawasaki Med. J., 9: 1-10.

GARRY, R. C. (1933) The responses to stimulation of the caudal end of the large bowel in the cat. J. Physiol. (Lond.), 78: 208-224.

de Groat, W. C. and KrIer, J. (1975) Preganglionic C-fibres: A major component of the sacral autonomic outflow to the colon of the cat. Pflügers Arch., 359: 171-176.

DE GroAt, W. C. and KRIER, J. (1976) An electrophysiological study of the sacral parasympathetic pathway to the colon of the cat. J. Physiol. (Lond.), 260: 425-445.

DE GroAT, W. C. and KRIER, J. (1978) The sacral parasympathetic reflex pathway regulating colonic motility and defecation in the cat. J. Physiol. (Lond.), 276: 481-500.

OKada, H., Fukuda, H., and Yamane, M. (1975) The efferent activity in the pelvic nerves during the recto-rectal reflex of the dog. Auton. Nerv. Syst., 12: 278-287 (in Japanese).

Okada, H., Fukuda, H., and Yamane, M. (1976) On the localization of the pontine defecation reflex center of the dog. Auton. Nerv. Syst., 13: 24-31 (in Japanese).

Vol. 35, No. 5, 1985 